\title{
Research on the Interactive Model of Taxable Income Adjustment and Temporary Difference Increment
}

\author{
Peng Zhao*, Zhiping Jiang, Shiqing Huang \\ Yinxing Hospitality Management College of CUIT \\ Chengdu, China, 611743
}

\begin{abstract}
We develop a model to analyze the interactive relationship between the taxable income adjustment based on income statement and the increment of temporary difference based on balance sheet. The results indicate that: in each period, the temporary taxable income adjustment equals the income tax-related temporary difference increment, and the adjustment of temporary income tax in each period equals the income tax-related deferred income tax item. These equivalent relationships can restrict neither the value of the permanent taxable income adjustment and its corresponding income tax adjustment, nor the temporary difference increment irrelative to income tax and its corresponding deferred income tax item increment. We also reveal how to use this model in the practice of income tax accounting by typical case study.
\end{abstract}

Keywords-Taxable Income Adjustment; Temporary Difference; Income Tax Adjustment; Deferred Income Tax Item

\section{INTRODUCTION}

Balance sheet liability method gets started respectively from the income statement dimension and the balance sheet dimension [1]. The former follows the direction of adjusting accounting profit to taxable income and then converting it into current income tax expense. The latter focuses on how temporary difference evolves into deferred income tax increment which may affect income tax expense or other comprehensive income [2]. Though there are many papers discussing the income tax from different perspectives, few literatures adopt the "interactive perspective" between the above mentioned dimensions. So, it is hard to answer questions, such as: "What is the relationship between the adjusted value of taxable income and the temporary difference increment?" and so on. In this paper, we propose a model to analyze the interactive relationship between taxable income adjustment and temporary difference increment, and illustrate its application in income tax accounting practice.

\section{Model of TAXABle InCOME AdJUSTMENT AND TEMPORARY DIFFERENCE}

\section{A. Definition of model variables}

In order to facilitate the discussion of the quantitative relationships in the amount of taxable income adjustment and temporary differences in income tax accounting, we define the following variables:

TABLE I. MODEL VARIABLES DEFINITION

\begin{tabular}{|c|c|c|c|}
\hline Variable & Variable description & Variable & Variable description \\
\hline PFA & Profits from the angle of accounting & TBA & Tax burden from the accounting perspective equals PFA*t \\
\hline PFT & Profits from the angle of tax law & TBT & Tax burden from tax law equals PFT*t \\
\hline TV & Total adjusted value of taxable income & TVT & Adjusted tax burden equals TV*t \\
\hline PA & Permanent adjusted value of taxable income & PAT & The permanent income tax adjustment equals PA* $t$ \\
\hline TA & Temporary adjusted value of taxable income & TAT & The temporary income tax adjustment equals TA*t \\
\hline $\mathrm{X}$ & Deferred income tax liabilities increments & $\mathrm{Y}$ & Deferred income tax assets increments \\
\hline $\mathrm{Z}$ & The total amount of income tax-irrelative portion in X-Y & $\mathrm{t}$ & Income tax rate \\
\hline $\mathrm{M}_{\mathrm{i}}$ & The amount recognized by the accounting standards for traction $\mathrm{i}$ & $\mathrm{M}_{\mathrm{i}}{ }^{\prime}$ & The amount recognized by the tax law for traction $\mathrm{i}$ \\
\hline
\end{tabular}

For a certain accounting period, if the tax law and accounting standards are inconsistent only at the time of tax confirmation, the tax payment will not affect the accounting. At this time, taxable income adjustment denoted by TA is temporary.

Because income tax law is in superior hierarchy than accounting standards, if the tax law changes the total amount of tax payments during the accounting period covered by the entire duration of an asset (or liability) by force [3], the tax payment affects the accounting and the taxable income adjustment denoted by $\mathrm{PA}$ is permanent.

This research is funded by the scientific research project (No.18SA0044) of Sichuan Provincial Department of Education, China.
Obviously, TV in each period is equal to the sum of TA and PA, and the positive (or negative) numbers of TV, PA and TA represent the increase (or decrease) on the basis of accounting profits. According to the above variable definitions and basic accounting knowledge, it's easy to know that PFA plus TV equals PFT, TBA plus TVT equals TBT, PA plus TA equals TV and PAT plus TAT equals TVT [4].

\section{B. Model Analysis Framework}

Giving the following analytical framework diagram, as shown in Fig.1, we will prove the quantitative relationships between the taxable income adjustment and temporary difference increment step by step. The bidirectional arrows in 
the figure indicate that the connected variables in the box can be inferred from each other, the one-way arrows represent our accounting calculation process and the parentheses indicate the combination of variables. In this paper, we place the focus on: Under the interference of the variables PAT and Z, what's the relationship between the temporary income tax adjustment value "TAT" and the tax-related increment of deferred income tax item "X-Y-Z"? What's the inter-quantitative relationship between the adjustment of temporary taxable income "TA" and the tax-related temporary difference increment " $(\mathrm{X}-\mathrm{Y}-\mathrm{Z}) / \mathrm{t}$ ”?

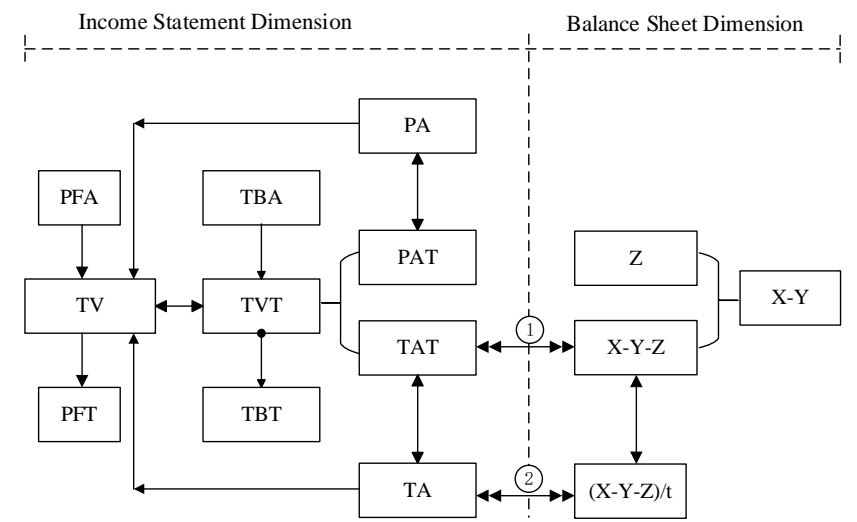

Fig. 1. Analytical framework for taxable income adjustment and temporary difference

\section{THEORY OF TAXABLE INCOME ADJUSTMENT AND TEMPORARY DIFFERENCE INTERACTIVE MODEL}

According to the definitions of variables and the focal issues in the above mentioned frame diagram, combination of $(0,0),(0, \neq 0)$ and $(\neq 0,0$ or $\neq 0)$ for $(P A T, Z)$ constitutes a complete division of set $\{$ TBA, PAT, TBT, X, Y, Z\}. So, we can discuss the relationships between taxable income adjustment and temporary difference under different (PAT, Z) in sequence, and then we aggregate them to get a complete interactive relationship model.

\section{A. As $P A T=0, Z=0$}

As PAT and Z are both equal to zero, tax expense don't affect accounting, temporary difference and its corresponding deferred income tax item only affect income tax. We start from this simplest case and the model is the basic model I, its mathematical expression such as formula (1).

$$
\mathrm{TBA}_{\mathrm{I}}-\mathrm{TBT}_{\mathrm{I}}=\mathrm{X}_{\mathrm{I}}-\mathrm{Y}_{\mathrm{I}}
$$

During a certain accounting period, if there are u pieces of transactions or events satisfying the model I, without loss of generality, for any i $(i=1,2,3, \ldots u)$, it's assumed that the amount based on accounting standards is $\mathrm{M}_{\mathrm{i}}$ while the amount in accordance with tax law is $M_{i}$ '. So $M_{i}$ minus $M_{i}{ }^{\prime}$ equals delta $M_{i}, M$ equals the sum of $M_{i}$, delta $M$ equals the sum of delta $M_{i}$, X equals the sum of $X_{i}$, Y equals the sum of $Y_{i}$.Using the general entry style, we get:

Debit: profits or losses (such as management expenses, etc.) $M_{i}\left(M_{i}{ }^{\prime}\right)$

Credit: assets (liabilities) (such as accumulated depreciation, etc.) $M_{i}\left(M_{i}^{\prime}\right)$
When delta $\mathrm{M}_{\mathrm{i}}>(<) 0$, the amount of profits and losses items measured according to accounting standards is larger (smaller) than the amount of such items approved by the tax law, which will lead to a smaller (larger) accounting profits in respect of the tax law. Therefore, the accounting profits should be increased (decreased) delta $\mathrm{M}_{\mathrm{i}}$ (its absolute value represents the amount, and the positive or negative sign represents the direction to increase or decrease), so as to pay more (less) income tax equivalent to delta $\mathrm{M}_{\mathrm{i}}$ multiplying tax rate $\mathrm{t}$. Adding all the $\mathrm{u}$ pieces of $\mathrm{u}$ tractions or events, we conclude that $\mathrm{TV}_{\mathrm{I}}$ equals the sum of delta $\mathrm{M}_{\mathrm{i}}$ and $\mathrm{TVT}_{\mathrm{I}}$ equals the sum of delta $\mathrm{M}_{\mathrm{i}}$ multiplying tax rate $\mathrm{t}$. The book value of assets (liabilities) is smaller (larger) than their tax bases, which forms deductible (taxable) temporary difference increment $\mathrm{M}_{\mathrm{i}}$. The deferred income tax item increment is $X_{i}$ minus $Y_{i}$ equals negative delta $M_{i}$ multiplying tax rate t. For all the $u, X_{I}$ minus $\mathrm{Y}_{\mathrm{I}}$ equals the sum of $\mathrm{X}_{\mathrm{i}}$ minus the sum of $\mathrm{Y}_{\mathrm{i}}$, and also equals negative delta $M_{i}$ multiplying tax rate $t$ or $T A V_{I}$. Considering TBA plus TVT equals TBT, hence, the model I gets work. We can draw the same conclusion if we exchange the debit and credit directions of the above general entry.

\section{B. As $P A T=0, Z \neq 0$}

Under such circumstances, taxation will not affect accounting, but temporary difference and their corresponding deferred income tax item affect both income tax expense and income tax-irrelative item. When $\mathrm{Z}$ doesn't equal to zero, incremental business to model I can be generalized as model II in formula (2).

$$
\mathrm{TBA}_{I I}-\mathrm{TBT}_{\mathrm{II}}=\mathrm{X}_{\mathrm{II}}-\mathrm{Y}_{\mathrm{II}}-\mathrm{Z}_{\mathrm{II}}
$$

During a certain accounting period, if there are $\mathrm{v}$ pieces of transactions or events satisfying the model II, without loss of generality, for any $\mathrm{j}(\mathrm{j}=1,2,3, \ldots \mathrm{v})$, it can be described by general entry style as follows:

Debit: assets (liabilities) (such as “available-for-sale financial assets-fair value changes”, etc.) $\mathbf{M}_{\mathrm{j}}$ $\left(\mathrm{M}_{\mathrm{j}}\right)$

Credit: other comprehensive income, capital reserves, goodwill, etc. $\mathrm{M}_{\mathrm{j}}\left(\mathrm{M}_{\mathrm{j}}{ }^{\prime}\right)$

The entry has nothing to do with the profit and loss accounts, which leads to no taxable income adjustment from the dimension of income statement. So the $\mathrm{TV}_{\mathrm{II}}$ and $\mathrm{TVT}_{\mathrm{II}}$ both equal to zero. The amount of assets (liabilities) recognized by the accounting standards is larger (smaller) than that approved by the tax law, thus the accounting book value of assets (liabilities) is larger (smaller) than the its tax basis. As a result, the temporary difference increment of taxable (deductible) is delta $\mathrm{M}_{\mathrm{j}}$ and deferred income tax item increment, which equals $\mathrm{X}_{\mathrm{j}}$ minus $\mathrm{Y}_{\mathrm{j}}$ and also equals delta $\mathrm{M}_{\mathrm{j}}$ multiplying tax rate $t$, will be all used to adjust income tax-irrelative item $Z_{j}$, such as comprehensive income.

Adding all the $\mathrm{j}$ pieces of $\mathrm{v}$ tractions or events, we can conclude that $\mathrm{TBA}_{\| I}$ minus $\mathrm{TBT}_{I I}$ equals the sum of $\mathrm{X}_{\mathrm{j}}$ minus the sum of $Y_{j}$, and then minus the sum of delta $M_{j}$ multiplying tax rate $t$, which also equals $X_{I I}$ minus $Y_{I I}$ and $Z_{I I}$. All the expressions here have the same value of zero. 
TBA-TBT+PAT $=\mathrm{X}-\mathrm{Y}-\mathrm{Z}=-\mathrm{TAT}$

Based on the above analysis, when $\mathrm{Z}=0$, model II can be reduced to model I. So no matter what $\mathrm{Z}$ is, model II always stands up.

\section{As $P A T \neq 0, Z=0$ or $\neq 0$}

PAT doesn't equal to zero, which indicates that the tax law has permanently changed the taxable income from the angle of accounting by utilizing its higher legal status. PAT should be incorporated into a new model. For instances, the amortization of intangible assets from the view of tax law can be added an extra $50 \%$ than that from the view of accounting but the administrative penalty can't be deducted from income before tax, etc. When PAT doesn't equal to zero, incremental business to model II can be generalized as model III in formula (3).

$$
\mathrm{TBA}_{\mathrm{II}}-\mathrm{TBT}_{\mathrm{II}}+\mathrm{PAT}_{\mathrm{III}}=\mathrm{X}_{\mathrm{III}}-\mathrm{Y}_{\mathrm{III}}-\mathrm{Z}_{\mathrm{III}}
$$

During a certain accounting period, if there are w pieces of transactions or events satisfying the model III, without loss of generality, for any $\mathrm{k}(\mathrm{k}=1,2,3, \ldots \mathrm{w})$, it can be described by general entry style as follows:

Debit: profits and losses (such as management expenses, etc.) $M_{k}\left(M_{k}{ }^{\prime}\right)$

Credit: assets (liabilities) (such as accumulated depreciation, etc.) $M_{k}\left(M_{k}{ }^{\prime}\right)$

When delta $\mathrm{M}_{\mathrm{k}}>(<) 0$, the amount of profits and losses items measured according to accounting standards is larger (smaller) than the amount of such items approved by the tax law, which will lead to a smaller (larger) accounting profit in respect of the tax law. Therefore, the accounting profits should be increased (decreased) delta $\mathrm{M}_{\mathrm{k}}$ (its absolute value represents the amount, and the positive or negative sign represents the direction to increase or decrease) permanently, so as to pay more (less) income tax equivalent to delta $\mathrm{M}_{\mathrm{k}}$ multiplying tax rate t. Adding all the $\mathrm{w}$ pieces of tractions or events, we can conclude that $\mathrm{TV}_{\text {III }}$ equals $\mathrm{PA}_{\text {III }}$ with the value of delta $\mathrm{M}_{\mathrm{k}}$ and TVT $_{\text {III }}$ equals $\mathrm{PAT}_{\text {III }}$ with the value of delta $\mathrm{M}_{\mathrm{k}}$ multiplying tax rate t. Because $\mathrm{TBA}_{\text {III }}$ minus $\mathrm{TBT}_{\mathrm{III}}$ plus $\mathrm{TVT}_{\mathrm{II}}$ equals zero, $\mathrm{TBA}_{\text {III }}$ minus $\mathrm{TBT}_{\text {III }}$ plus $\mathrm{PAT}_{\text {III }}$ as the left of model III equals zero also.

In model III, the temporary difference is essentially permanent without any deductible or taxable inclination. Apparently, the increment is $-\Delta \mathrm{M}_{\mathrm{k}}$, but the tax law stipulates that such increment is either zero, such as administrative penalty, or no further confirmation of deferred income tax items, such as the extra amortization of intangible assets. Adding w pieces of this kind of business, we can infer that $X_{\text {III }}$ minus $Y_{\mathrm{III}}$ and then minus $Z_{\mathrm{III}}$ as the right of model III equals zero, therefore model III stands up.

\section{Generalized model}

When PAT and Z are arbitrarily valued, compared to Model I (I I), the incremental part of Model II (III) stands up. Superposing all the above three models with their left and right side respectively, we can get the general model IV, which is suitable for all kinds of situations. Model I, II, III can be understood as some special cases of model IV under certain circumstances.
According to the variables definitions, model IV can be also expressed as formula (5) or (6).

$$
\begin{aligned}
& \text { TBA-TBT+PAT=X-Y-Z=-TAT } \\
& -\mathrm{TA}=(\mathrm{X}-\mathrm{Y}-\mathrm{Z}) / \mathrm{t}
\end{aligned}
$$

From the formula (5) and (6), we can conclude that: in each period, the temporary taxable income adjustments equal to the income tax-related temporary differences increments, and the adjustments of temporary income tax in each period equal to the income tax-related deferred income tax items. These equivalent relationships can restrict neither the value of any permanent taxable income adjustment and its corresponding income tax adjustment, nor any temporary difference increment irrelative to income tax and its corresponding deferred income tax item increment.

\section{Model Application CASe}

\section{A. Case Description}

In 2017, the sales revenue of an intelligent equipment company was 40 million Yuan and accounting profit was $10 \%$ of the sales revenue with applicable $17 \%$ of value-added tax rate and $25 \%$ of the income tax rate. It was expected that the deferred income tax assets would be deductible totally in future and the deferred income tax items had no initial balance. The company had income tax relevant transactions or events as follows:

(1) The self-developed office system was put into use at the beginning year 2017 and the capitalized development expenditure was 8 million Yuan. It would be amortized in 10 years and the tax law allowed an extra 50\% amortization than the sum of relevant accounting standard.

(2) On December 20, 2016, the production line with the worth of 3.2 million Yuan reached its usable state. Estimated life was 8 years and net salvage rate was $10 \%$. The straight-line method prescribed by the tax law whiles the sum-of-the-years-digits method by the accounting standard.

(3) The invoice had been issued and the money had been deposited in the bank for a batch of sold goods at the price (cost) of $0.64(0.48)$ million Yuan. Though the sales didn't meet the income recognition conditions of the accounting standards, the tax liability occurred.

(4) Purchased stock at the price of 0.84 million Yuan was categorized as available-for-sale financial assets and increased its market value to 1 million Yuan at the end of the year 2017.

(5) The actual advertising expenditure was 7.6 million Yuan.

(6) It's estimated to be fined 0.80 million Yuan for violating the Environmental Protection Law.

(7) At the end of 2017, 0.32 million Yuan was reserved for the falling price of the inventory.

Please make an income tax analysis on the above transactions or events with the monetary unit of million Yuan. 


\section{B. Case Analysis}

The accounting standard (tax law) approval amount is placed outside (in) the brackets.

(1) The amortization difference between accounting standards and tax law.

Debit: management fee 0.80 (1.20)

Credit: accumulated amortization of 0.80 (1.20)

The tax law allows an additional 50\% mandatory deduction on the basis of the accounting amortization, so $\mathrm{PA}_{1}=-0.40$ while $\mathrm{Y}_{1}=0$.

(2) Depreciation difference between accounting standards and tax law.

Debit: management fee $0.64(0.36)$

Credit: accumulated depreciation 0.64 (0.36)

Different depreciation methods lead to different depreciation amount, TA2 $=0.28$. Accounting book value of the production line was 2.56, less than its tax base of 2.84, $\mathrm{Y} 2=0.07$.

(3) Confirmation difference of revenue (cost) between accounting standards and tax law.

Debit: merchandise shipped 0.48 (main business cost 48)

Credit: commodity stocks 0.48

Debit: bank deposit 0.7488

Credit: deposit received 0.64 (main business income 0.64 ) tax payable - VAT payable (output tax) 0.1088

Under the tax law, the income and cost were respectively 0.64 and 0.48 , and $\mathrm{TA}_{3}=0.16$. The book value of the inventory was 0.48 Yuan larger than its tax base, forming a taxable temporary difference of 0.48 , so $X_{3}=0.12$. The book value of the deposit received was 0.64 and the tax base was zero, which can generate deductible temporary difference of 0.64 , so $\mathrm{Y}_{3}=0.16$.

(4) The change in fair value of the relevant asset shall be approved by the tax law only at its disposal.

Debit: cost of available-for-sale financial assets $0.84(0.84)$

Credit: bank deposit 0.84(0.84)

Debit: fair value change of available for sale of financial assets $0.16(0)$

Credit: other comprehensive income $0.16(0)$

No impact on the profits and losses, no need to adjust the accounting profits, $\mathrm{X}_{4}=\mathrm{Z}_{4}=0.04$.

(5) The tax law allows advertising expenses to be deducted before tax within the range of $15 \%$ of the current sales revenue and the excess portion to be deducted before tax in subsequent periods.

Debit: sales fee 7.60 (6.00)

Credit: bank deposit 7.60 (6.00)

$\mathrm{TA}_{5}=1.6$. The excess advertising fee of 1.6 million yuan should be deducted before tax in next year and the excess income tax paid in 2017 should be regarded as deferred income tax assets, $Y_{5}=0.40$.

(6) The penalty of violating the Environmental Protection Law shall not be deducted before tax.

Debit: non-operating expenses $0.80(0)$

Credit: estimated liability $0.80(0)$
$\mathrm{PA}_{6}=0.8$. The book value of the expected liabilities was equal to its tax base, so the temporary difference was zero, $\mathrm{X}_{6}=\mathrm{Y}_{6}=0$.

(7) Asset impairment loss of inventory shall be recognized at its disposal.

Debit: assets impairment loss $0.32(0)$

Credit: inventory falling price reserves $0.32(0)$

$\mathrm{TA}_{7}=0.32$. Assuming the historical cost of inventory was $\mathrm{H}$, accounting book value $=\mathrm{H}-0.32$ would generate a deductible temporary difference of $0.32, \mathrm{Y}_{7}=0.08$.

(8) Comprehensive analysis

$\mathrm{TBA}+\mathrm{PAT}=\left(\mathrm{PFA}+\Sigma \mathrm{PA}_{\mathrm{i}}\right) * \mathrm{t}=(4.0-0.40+0.80) * 25 \%=1.10$

TBT $=\mathrm{PFT}^{*} \mathrm{t}=\left(\mathrm{PFA}+\Sigma \mathrm{PA}_{\mathrm{i}}+\Sigma \mathrm{TA}_{\mathrm{i}}\right) * *_{\mathrm{t}}=$

$(4.00-0.40+0.80+0.28+0.16+1.60+0.32) * 25 \%=1.69$

$\mathrm{X}=\Sigma \mathrm{X}_{\mathrm{i}}=0.12+0.04=0.16, \mathrm{Y}=\Sigma \mathrm{Y}_{\mathrm{i}}$

$=0.07+0.16+0.40+0.08=0.71, Z=\Sigma Z_{i}=0.04$

Debit: income tax expenses 1.10 (TBA+PAT)

Deferred income tax asset $0.71(\mathrm{Y})$

Other comprehensive income $0.04(\mathrm{Z})$

Credit: deferred income tax liability 0.16 (X) tax payable-income tax 1.69 (TBT)

\section{Conclusion}

By gradually relaxing the assumptions and examining the incremental transactions between different models, we have logically proved the quantitative inter-relationship between the taxable income adjustment of the income statement dimension and the temporary difference increment of the balance sheet dimension in the income tax accounting. The theoretical analysis shows that the adjusted value of the temporary taxable income equals the income tax-relevant temporary difference increment. Temporary income tax adjustment equals the income tax-relevant incremental value of deferred income tax items. The relationships can neither constrain permanent taxable income adjustment and its corresponding values of income tax adjustment, nor the tax-irrelevant temporary difference and its deferred income tax increment. The case study reveals that the amount of income tax expenses is equal to the accounting profits of the current period plus the permanent taxable income adjustments multiplied by the tax rate, which has nothing to do with any temporary taxable income adjustment. The amount of each entry will naturally achieve the balance on the basis of satisfying its own logical components.

\section{REFERENCES}

[1] China Institute of Certified Public Accountants. Accounting. China Finance and Economics Press, Beijing, 2018.

[2] Ministry of Finance, P. R. China, Accounting Standard for Business Enterprises: No.18-Income Taxes, Economic Science Press, Beijing, 2006

[3] China Institute of Cert ified Public Accountants. Tax law. China Finance and Economics Press, Beijing, 2018.

[4] Ministry of Finance. Guide to the Application of Accounting Standards for Enterprises. Lixin Accounting Press, Shanghai, 2018. 